IZA DP No. 7625

Self-Serving Use of Equity Rules in Bargaining with Asymmetric Outside Options

Heike Hennig-Schmidt

Bernd Irlenbusch

Rainer Michael Rilke

Gari Walkowitz

September 2013 


\title{
Self-Serving Use of Equity Rules in Bargaining with Asymmetric Outside Options
}

\author{
Heike Hennig-Schmidt \\ BonnEconLab, University of Bonn \\ Bernd Irlenbusch \\ University of Cologne and IZA
}

Rainer Michael Rilke

University of Cologne

Gari Walkowitz

University of Cologne and BonnEconLab

Discussion Paper No. 7625
September 2013

IZA

P.O. Box 7240

53072 Bonn

Germany

Phone: +49-228-3894-0

Fax: +49-228-3894-180

E-mail: iza@iza.org

Any opinions expressed here are those of the author(s) and not those of IZA. Research published in this series may include views on policy, but the institute itself takes no institutional policy positions. The IZA research network is committed to the IZA Guiding Principles of Research Integrity.

The Institute for the Study of Labor (IZA) in Bonn is a local and virtual international research center and a place of communication between science, politics and business. IZA is an independent nonprofit organization supported by Deutsche Post Foundation. The center is associated with the University of Bonn and offers a stimulating research environment through its international network, workshops and conferences, data service, project support, research visits and doctoral program. IZA engages in (i) original and internationally competitive research in all fields of labor economics, (ii) development of policy concepts, and (iii) dissemination of research results and concepts to the interested public.

IZA Discussion Papers often represent preliminary work and are circulated to encourage discussion. Citation of such a paper should account for its provisional character. A revised version may be available directly from the author. 
IZA Discussion Paper No. 7625

September 2013

\section{ABSTRACT}

\section{Self-Serving Use of Equity Rules in Bargaining with Asymmetric Outside Options}

We experimentally investigate multiple notions of equity in ultimatum bargaining with asymmetric outside options. Building on the generalized equity principle formulated by Selten (1978), we derive three different equity rules that can explain $43 \%$ of all offers. Our withinsubject design further allows us to show that proposers use different equity rules and apply them in a self-serving manner. They tend to follow the rules that suggest the highest payoff for them. Responders exhibit a similar pattern of behavior. Combined, these tendencies lead to high inefficiencies due to frequent rejections.

JEL Classification: $\quad$ C71, C72, C78, C91, D63

Keywords: $\quad$ Outside Options, Equity Principle, Ultimatum Game

Corresponding author:

Rainer Michael Rilke

University of Cologne

Department of Corporate Development and Business Ethics

Albertus-Magnus-Platz

50923 Cologne

Germany

E-mail: rainer.rilke@uni-koeln.de

\footnotetext{
* We are grateful to Ralph Bayer, Julia Berndt, Julian Conrads, Anastasia Danilov, Sven Fischer, Reinhard Selten, Matthias Sutter and the seminar participants at various conferences for their valuable comments and suggestions. Financial support from the Deutsche Forschungsgemeinschaft through grant 'TP3 Design of Incentives Schemes within Firms: Bonus Systems and Performance Evaluations' (sub-project of the DFG-Forschergruppe 'Design and Behavior') and through the Leibniz-Award to Axel Ockenfels is gratefully acknowledged.
} 
"Whatever I judge reasonable or unreasonable for another to do to me; that, by the same judgment, I declare reasonable or unreasonable, that I in the like case should do for him."

(Samuel Clarke, A Discourse Concerning the Unchangeable Obligations of Natural Religion, and the Truth and Certainty of the Christian Revelation, London, 1706; $10^{\text {th }}$ ed., 1749)

\section{Introduction}

Experienced negotiators are well aware of the fact that lucrative alternatives in the case of a bargaining breakdown strengthen their own bargaining position. Authoritative manuals of successful negotiation strategies even recommend that one should strive for such outside options before entering into a bargaining situation (Fisher and Ury, 1991; Malhortra and Bazerman, 2008). Although experts and common wisdom suggest that outside options constitute an important determinant of bargaining outcomes, only very limited systematic research has examined bargaining behavior when outside options are available. Why are outside options important for bargaining outcomes? How do bargainers take outside options into account? What happens if outside options are asymmetric ( i.e., if different parties have outside options with different monetary values)? Do different constellations of outside options trigger different distribution rules? If so, which distribution rules are applied, and do individuals apply them in a consistent manner? How does the constellation of outside options affect the outcome of a negotiation, and how does it affect the likelihood of reaching an agreement in the first place?

Think, for example, of a manager searching for a new job and an employer looking for a manager to run a new subunit. In the new job, the manager would generate a certain profit that could be divided between her and the new employer. The parties have asymmetric outside options; for example, the manager holds an offer from somewhere else, and the employer could realize gains from outsourcing the planned activity. Let us suppose that both parties have a good estimate of the value of each others' outside options (e.g., the potential employer might have an exact estimation of the market value of the manager, and the manager has insider information on gains from outsourcing). Let us further assume that the sum of the outside options of the two parties is smaller than the profit that they could generate together (i.e., hiring the manager is efficient). Do the outside options have an influence on how the profit is divided? One might think of various arguments that suggest different divisions. For example, one could argue that the profit should be equally divided (equal split) because both parties are needed to generate the profit. Alternatively, one might guarantee the outside options for each party and divide the remainder equally (split the difference). A third method would be to divide the profit proportionally relative 
to the outside options (proportional split). Would the negotiators follow one of these rules? If yes, which one would they apply?

Or, consider two situations that differ in the outside options of the two parties. What if, in the first situation, the manager has a much better outside option than the employer, but, in the second situation, it is exactly the other way around? Would the manager consistently apply the same rule across both situations? These are the questions which we address in this paper.

In our analysis on bargaining with outside options, we concentrate on the three previously discussed distribution rules. We refer to the three rules as equity rules namely, equal split, split the difference, and proportional split. One reason for this focus is that the relevance of these three rules has frequently been observed in previous studies (for a survey, see Konow, 2003). A second reason is that all three rules follow a similar logic: All three can be derived from the generalized equity principle proposed by Selten (1978). The generalized equity principle relies on accepted positive weights (Selten refers to them as a 'standard of comparison') assigned to each party involved in the negotiation. The weights can reflect different characteristics of the bargaining situation, such as the number of people represented by one party, the magnitude of the outside options, and a measure of power or individual contributions to a joint project in terms of money or effort. A final distribution (Selten calls it a 'standard of distribution') of an amount satisfies the generalized equity principle if the ratio between the individual payoff and the individual weight is equal for all involved parties. $^{1}$ In section 3 , we explain how the three equity rules can be derived from the generalized equity principle by employing different weights and by varying the amount to which the generalized equity principle is applied. To keep the bargaining situation simple, we employ the ultimatum game (Güth et al., 1982) as our workhorse. ${ }^{2}$ A proposer $i$ and a responder $j$ bargain over an amount of money $a$. The proposer makes an offer $a_{j} \leq a$ to the responder. If the responder accepts, she receives $a_{j}$ and the proposer receives $a_{i}=a-a_{j}$. If the responder rejects the offer, both players receive their respective outside options, i.e., the proposer receives $o_{i}$ and the responder receives $o_{j}$. In the standard ultimatum game, the

\footnotetext{
${ }^{1}$ The criterion of proportionality that underlies the generalized equity principle goes back at least to Aristotle, (Nicomachean Ethics, V, 5): "Let A be a builder, B a shoemaker, C a house, D a shoe. The builder, then, must get from the shoemaker the latter's work, and must himself give him in return his own. If, then, first there is a proportionate equality of goods, and the reciprocation takes place, the result will be 'equality.' If not, the bargain is not equal, and does not hold; for there is nothing to prevent the work of the one being better than that of the other; they must therefore be equated." Later, proportionality in exchange was prominently featured in many disciplines, in philosophy (Soudek, 1952), sociology (Homans, 1958; Deutsch, 1975; Cook and Hegtvedt, 1983), social psychology (Adams, 1965; Walster et al., 1973; Messick, 1993) and economics (Young, 1995; Konow, 2000, 2003).

2Related empirical studies use the 'claims problem' (also called the 'bankruptcy problem') to study equity norms in bargaining (for example, Gächter and Riedl, 2005, 2006; Bosmans and Schokkaert, 2009; for an extensive discussion, see also Gärtner and Schokkaert, 2012). In our ultimatum games, the sum of outside options is always smaller than the total amount available and, thus, an agreement increases efficiency. In the claims problem the situation is different because the sum of claims exceeds the available amount.
} 
outside options of both players are equal to zero (i.e., with regard to the outside options, both players have equal bargaining strength).

A large number of experimental studies have looked into the behavior within the standard ultimatum game and found a clear predominance of equal payoff offers (see, for example, Güth and Tietz, 1990; Güth, 1995). In light of the generalized equity principle, this result does not come as a surprise because, for the standard ultimatum game, all three equity rules discussed herein suggest the same outcome: equal shares for both players.

In our experiment, we employ five different ultimatum games as our treatments. Proposer and responder bargain over a total amount of 240 points. Treatments vary the size of the higher outside option (either 150 or 90 points; the lower outside option is always 30 points) and the player who has the larger outside option (i.e., the proposer or the responder). In addition, we run a treatment where both outside options are 30 points, i.e., symmetric. Another feature of our experiment is that every participant runs through two ultimatum games with different outside option constellations, which enables us to trace equity notions of one individual under different circumstances.

The parametrization of our treatments guarantees that $(i)$ for the asymmetric ultimatum games the three equity rules provide three different point predictions, (ii) in the symmetric game the proportional split is applicable, i.e., the outside options are different from zero, (iii) the sum of the outside options is smaller than the total amount available, i.e., agreement increases efficiency and $(i v)$ in some of the treatments, one outside option is larger than the equal split.

We designed our treatments to investigate three important issues of bargaining with outside options. First, we analyze whether the generalized equity principle captures the behavior observed and, if so, which of the three equity rules are applied under the various outside option constellations. Second, in a within-subject comparison we investigate whether individuals consistently apply the equity rules if they take part in two ultimatum games that differ in their outside option constellations. Finally, we study the interplay among outside options, equity rules and rejection behavior.

One of our main findings is that the generalized equity principle proposed by Selten (1978) reflects the behavior in our experiment remarkably well. Overall, $43 \%$ of observed offers correspond to the point predictions of one of the three equity rules. In the symmetric games, most proposers offer the equal split. This behavior is predicted by all three equity rules. When comparing the behavior from the asymmetric ultimatum games across treatments, it becomes evident that not one single equity rule is prevalent. The data suggest that a proposer tends to apply the equity rule that benefits her most. ${ }^{3}$ More precisely,

\footnotetext{
${ }^{3}$ The self-serving use of fairness in bargaining underlines similar findings from related work (see, for example, Messick and Sentis, 1979; Babcock et al., 1995, 1996; Babcock and Loewenstein, 1997; Pillutla and
} 
the majority of proposers opt for a proportional division when they have the larger outside option of either 150 or 90 . However, when the responder has the larger outside option, proposers tend to suggest splitting the endowment equally. Regarding the rejection behavior of responders, we observe high rates of rejection in games with outside options of 150 namely, in games in which the responder has an outside option that is larger than the equal split. Responders, too, tend to adopt the equity rule that favors them. This self-serving use of the equity rules by the proposers and responders often leads to rejections, i.e., inefficient bargaining outcomes. Concerning profits and efficiency gains, we find that having a large outside option, i.e., 150 does not lead to significant improvements. This finding sheds new light on the common understanding that better outside options are desirable.

In the next section, we will discuss the literature related to our work. Section 3 introduces the generalized equity principle by Selten (1978) and applies it to ultimatum bargaining with outside options. Section 4 introduces our experimental design and the procedure. In Section 5 , we summarize our hypothesis. Section 6 presents our experimental findings, and Section 7 concludes the paper.

\section{Outside Options and Equity Rules}

Our review of related studies is guided by our main research questions. How do outside options shape bargaining behavior in ultimatum games? Do different equity rules explain bargaining behavior?

Only a very few studies have examined the effects of asymmetric outside options in ultimatum games (see Knez and Camerer, 1995; Schmitt, 2004; Kohnz and Hennig-Schmidt, 2005; Fischer, 2005). The results from these studies can be summarized as follows: Proposers decrease their offers when they have a larger outside option than the responder but increase their offers when responders have a larger outside option. In both cases, high rates of rejection are observed, suggesting that responders think that the offers are too low. However, these studies do not investigate how different equity rules relate to players' behavior in asymmetric ultimatum bargaining.

Different outside options appear to influence what the negotiators regard as reasonable divisions. Relatively little, however, is known about what these (incompatible) notions of reasonable divisions actually are that ultimately lead to the observed inefficiencies. Kagel et al. (1996) demonstrated that subjects try to enforce different seemingly 'fair' allocation rules. In these authors' ultimatum game experiment, they manipulated the exchange rates of the experimental currency unit for the two players. Consequently, the players can divide

Murnighan, 1995; Konow, 2000, 2005; Lange et al., 2010; Rodriguez-Lara and Moreno-Garrido, 2012; Rode and Menestrel, 2011). 
the pie according to an equal dollar split or, alternatively, according to an equal chip split. Their results effectively show that the subjects with a lower exchange rate try to enforce an equal dollar split, which would make them better off compared to the equal chip split. However, subjects that have been assigned the larger exchange rate try to adhere to the equal chip split. The authors observed that the disagreement over different distribution rules leads to frequent rejections.

The application of different distribution rules has also been investigated in other experimental games, e.g., in the claims problem and in the dictator game. The claims problem describes a situation where an amount of money can be distributed between players that have claims and where the amount to be distributed is smaller than the sum of these claims. Gächter and Riedl (2005; 2006) investigated the behavior of individuals in a claims problem when one player has a higher claim than the other. Claims are obtained by a quiz, i.e., players with the better performance receive the higher claim. After the quiz players engage in a negotiation in an open-form bargaining protocol. The results convincingly suggest that players agree most often on a proportional division, although other distribution rules are also feasible. ${ }^{4}$ Bosmans and Schokkaert (2009) studied the claims problem by asking students what they think is the most desirable distribution. Their results indicate that proportionality is a widely held normative judgment across different variants of the claims problem. In sum, the studies on the claims problem provide insights that proportional divisions are a good predictor for normative judgments and actual bargaining behavior.

Different distribution rules are also relevant to studies employing the dictator game (Konow, 2000). In the dictator game, a proposer unilaterally decides how to split an amount of money. Rodriguez-Lara and Moreno-Garrido (2012) investigated the self-serving selection of justice principles in an experimental dictator game. Before the proposer can distribute the amount, individuals take part in a quiz; a correct answer enlarges the total amount. Subjects differ in the way their (correct) answers on the quiz enlarge the amount (i.e., they differ in their productivity). Ex ante, the authors identify three different division rules based on a study by Cappelen et al. (2007). The egalitarian principle predicts that proposer and receiver end up with the same amount, irrespective of their productivity. The accountability principle holds subjects accountable for what they can control; in other words they can control the number of correct answers, but not the productivity, which is exogenously and randomly induced. Thus, a subject should receive an amount proportional to the number of her correct answers. The libertarian principle suggests that a subject should receive what she has 'produced' on the quiz. This principle does not differentiate between what a subject can influence (the number of correct answers) and what the subject cannot influence

\footnotetext{
${ }^{4}$ For example, one could distribute the total amount according to the equal split. Alternatively, the player with the smaller claim receives her full claim while the other subject receives the remainder (constrained equal award scheme).
} 
(the productivity). The results highlight a self-serving bias in justice assessments. When a proposer has a lower productivity compared to the recipient, the proposer tends to rely on an egalitarian distribution. Contrarily, when the proposer's productivity is higher than that of the recipient, the proposals can best be described by the libertarian or the accountability principle.

Hennig-Schmidt et al. (2010) survey video experiments on asymmetric outside options in alternating offer bargaining, triple take, power-to-take and ultimatum game experiments (see also Hennig-Schmidt et al. (2008)). The authors report that experimental subjects not only discuss equity-based division rules. The rules we are focusing on in the present paper are also decisive for participants' behavior. Moreover, it is equity-based allocations that subjects characterize as fair divisions. Finally, a comparison between Germany and China demonstrates cross-cultural validity of equity rules.

Taken together, the modest literature so far shows that different outside options appear to lead negotiators to disagree about what a 'reasonable' division might be. What the different notions of such distributions that tend to be perceived as fair (Hennig-Schmidt et al., 2010) in fact are and whether individuals are consistent in what they consider to be fair are still not well understood. We extend upon this literature by systematically applying the generalized equity principle of Selten (1978) to an ultimatum bargaining context with asymmetric outside options. The principle provides three distinct equity rules that follow an equity logic but lead to different distributions. Our approach deepens the understanding of how different equity notions are at work in bargaining situations. We are able to explore how different equity notions lead to inefficient bargaining outcomes. Our within-subject design also allows us to investigate whether an equity rule is consistently applied by a single individual across different outside option constellations.

\section{The Generalized Equity Principle in Ultimatum Bargaining with Outside Options}

In the following, we exemplify how the three equity rules can be derived from applying the generalized equity principle (Selten, 1978) to bargaining with (asymmetric) outside options. We focus on two players: $i$ (the proposer) and $j$ (the responder), who negotiate about how to divide an amount $a$.

The generalized equity principle proposes to balance the players' shares according to individual weights. ${ }^{5}$ Let $r \leq a$ be the amount of money that is to be distributed. The

\footnotetext{
${ }^{5}$ When the players' allocations are based on the assumption of common rationality and moneymaximization, proposers offer at least the outside option to the responder. Thus, applying the sub-game perfect equilibrium outcome (SP) yields a share for the responder of one unit more than her outside option.
} 
Table 1: Overview of equity rules from the perspective of player $i$

\begin{tabular}{lllllc}
\hline Equity Rule & & $r$ & $w_{i}$ & $r_{i}$ & $a_{i}$ \\
\hline Equal Split & (EQ) & $a$ & 1 & $\frac{r}{2}$ & $\frac{a}{2}$ \\
Split the Difference & (SD) & $a-o_{i}-o_{j}$ & 1 & $\frac{r}{2}$ & $o_{i}+\frac{1}{2} \cdot\left(a-o_{i}-o_{j}\right)$ \\
Proportional Split & (PS) & $a$ & $o_{i}$ & $\frac{o_{i}}{o_{i}+o_{j}} \cdot r$ & $\frac{o_{i}}{o_{i}+o_{j}} \cdot a$
\end{tabular}

Notes: $r$ is the amount to which the equity principle is applied; $\left(r_{i} ; r_{j}\right)$ is the standard of distribution, for player $i .\left(w_{i} ; w_{j}\right)$ denotes the standard of comparison, $a_{i}$ stands for the amount the player $i$ receives in the case of agreement, $o_{i}$ represents her outside option.

non-negative weights $w_{i}$ and $w_{j}$ of players $i$ and $j$ reflect a certain characteristic according to which the players can be compared(e.g., their outside options, the number of people represented by a player, a measure of power, contributions in a joint project). Selten (1978) calls the vector of weights the standard of comparison.

A standard of distribution is a vector $\left(r_{i}, r_{j}\right)$, with $r_{i}, r_{j} \geq 0$ and $r_{i}+r_{j}=r$. The generalized equity principle requires that

$$
\frac{r_{i}}{w_{i}}=\frac{r_{j}}{w_{j}}
$$

Thus, the standard of distribution with respect to player $i$ is given by $r_{i}=\frac{w_{i}}{w_{i}+w_{j}} \cdot r$.

Depending on the amount $r$ and the standard of comparison $w_{i}$ and $w_{j}$ at least three different distribution rules can be derived for ultimatum bargaining with outside options. The candidates for the amount $r$ are the complete amount, i.e., $r=a$, or the complete amount diminished by the respective outside options, i.e., $r=a-o_{i}-o_{j}$. Natural candidates for the weights are $w_{i}=w_{j}=1$ (because, e.g., each bargaining party is constituted by one individual) or $w_{i}=o_{i}$ and $w_{j}=o_{j}$ (since, e.g., outside options are likely to be a major source of bargaining power).

\section{Equal Split}

The Equal Split (henceforth EQ) results from the generalized equity principle when one assumes that both players have the same weight $w_{i}=w_{j}=1$ and that $r$ is equal to the total amount $a$. According to this equity rule, every player receives the same amount that is, $a_{i}=a_{j}=a / 2$.

The proposer would receive the rest of the complete amount. This result holds for the case that the amount to be distributed is infinitely divisible. Typically in experiments, bargaining units are integers. Thus, an offer of the size of the responder's outside option can also be an outcome of a sub-game perfect equilibrium. 


\section{Split the Difference}

The distribution rule Split the Difference (SD) emerges from the generalized equity principle when $r=a-o_{i}-o_{j}$ and players apply $w_{i}=w_{j}=1$. Player $i$ 's amount is then determined by $a_{i}=o_{i}+1 / 2\left(a-o_{i}-o_{j}\right)$ and player $j$ 's amount is $a_{j}=o_{j}+1 / 2\left(a-o_{i}-o_{j}\right)$. SD yields an unequal distribution if $o_{i} \neq o_{j}{ }^{6}$

\section{Proportional Split}

The Proportional Split (PS) can be derived from the generalized equity principle by using a standard of comparison based on the relative magnitude of outside options, i.e., $w_{i}=o_{i}$ and $w_{j}=o_{j}$ and by assuming that $r$ is equal to the total amount $a$ to be distributed. Each player's share represents her proportional bargaining power induced by her outside option. Player $i$ receives $a_{i}=a \cdot o_{i} /\left(o_{i}+o_{j}\right)$ and player $j$ receives $a_{j}=a \cdot o_{j} /\left(o_{i}+o_{j}\right)$. This equity rule also leads to an unequal distribution if $o_{i} \neq o_{j}$.

Note that EQ, SD and PS result in the same payoffs if, and only if, $o_{i}=o_{j} \cdot{ }^{7}$ In the standard ultimatum game, where $o_{i}=o_{j}$, the equal split appears to be prevalent (see Güth and Tietz, 1990; Güth, 1995).

\section{Experiment}

Experimental Design To systematically investigate the impact of outside options on the application of the equity principle in ultimatum bargaining, we in total investigate five treatments, each employing an ultimatum game with different outside option constellations. In all treatments, the amount $a$ to be distributed is equal to 240 points. The proposer decides on the amount she is willing to offer to the responder, while the responder simultaneously indicates the minimal offer she would be willing to accept ("mao"). If the proposer's offer exceeds this minimum acceptable offer, the 240 points are distributed according to the offer; otherwise, subjects receive their respective outside options.

In the Baseline treatment, both players have the same outside option of 30 points. In addition, we employ treatments with asymmetric outside options, where an outside option of one player is larger than the outside option of the other player. The smaller outside option is always 30 points. We systematically vary $(i)$ the sizes of the larger outside option (either 150 or 90 points) and (ii) the player who is endowed with the larger outside option (either Proposer or Responder). Taken together, this yields five treatments: Baseline, $P_{150}$,

\footnotetext{
${ }^{6}$ Assuming that the outside options can be regarded as threat points, the distribution rule SD also follows from the Nash bargaining solution (Nash, 1953) and the Shapley value (Shapley, 1953). For a discussion, see (Roth, 1988; Chiu and Yang, 1999; Anbarci and Feltovich, 2011).

${ }^{7}$ Note that PS is not applicable if both outside options are equal to zero.
} 
Table 2: Treatments and predictions of equity rules

\begin{tabular}{|c|c|c|c|c|c|c|c|c|}
\hline \multirow[b]{2}{*}{ Treatment } & \multirow[b]{2}{*}{$o_{i}$} & \multirow[b]{2}{*}{$o_{j}$} & \multicolumn{2}{|c|}{ EQ } & \multicolumn{2}{|c|}{ SD } & \multicolumn{2}{|c|}{ PS } \\
\hline & & & $a_{i}$ & $a_{j}$ & $a_{i}$ & $a_{j}$ & $a_{i}$ & $a_{j}$ \\
\hline Baseline & 30 & 30 & 120 & 120 & 120 & 120 & 120 & 120 \\
\hline$P_{150}$ & 150 & 30 & 120 & 120 & 180 & 60 & 200 & 40 \\
\hline$R_{150}$ & 30 & 150 & 120 & 120 & 60 & 180 & 40 & 200 \\
\hline$P_{90}$ & 90 & 30 & 120 & 120 & 150 & 90 & 180 & 60 \\
\hline$R_{90}$ & 30 & 90 & 120 & 120 & 90 & 150 & 60 & 180 \\
\hline
\end{tabular}

Notes: $o_{i}\left(o_{j}\right)$ represents the outside option of the proposer (responder). $a_{i}\left(a_{j}\right)$ is the share the proposer (responder) gets as a result of the respective equity rule.

$R_{150}, P_{90}$ and $R_{90}$. An overview of all treatments and the resulting equity rules is given in Table 2. Our parameterization has the unique feature to clearly separate the distinct outcomes derived by the equity principle. In particular, we are able to investigate their relevance when one of the outside options is below half of the total amount of 240 (i.e., 90) or when one of the outside options exceeds half of the total amount of 240 (i.e., 150).

In order to examine the application of equity rules between and within subjects, we employ the following experimental protocol. Each subject participates in a sequence of two different treatments interacting with two different counterparts (perfect stranger-matching protocol) without feedback on the counterpart's decision between treatments. We balance the order of the treatments to be able to control for order effects. Subjects are randomly assigned to the role of the proposer or the responder and they maintain their roles across treatments. $^{8}$

In total, we employ twelve different sequences of two treatments (each of our four asymmetric treatments is combined with Baseline in both orders; in addition, we combine the asymmetric treatments $P_{150}$ with $R_{150}$ and $P_{90}$ with $R_{90}$ in four sequences to control for order). An overview of all sequences can be found in Table A.1. Technically, in each sequence, two proposers and two responders form a matching group. Each participant interacts exactly once with each of the two participants with the other role.

Procedural Details Our experimental sessions involved 280 subjects from the University of Bonn in Germany ( $51 \%$ male, average age 24 years), who were recruited via the online

\footnotetext{
${ }^{8}$ We use a neutral language in the instructions and on the computer screens: Proposers are called "Player A" and responders are called "Player B" (see the Appendix for a translation of the instructions). The original instructions were provided in German and are available upon request.
} 
recruiting system ORSEE (Greiner, 2003). Each participant took part in only one of the sessions. The experiment was programmed using the software z-Tree (Fischbacher, 2007). Subjects' earnings were determined by summing of earnings in both treatments in which they participated. We applied an exchange rate of 10 points equal to $0.6 €$; thus, 240 points are worth $14.40 €$. On average, subjects earned $15.78 €$. At the beginning of the experiment, we handed out instructions and control questions to make sure that everyone understood the general rules of the games.

\section{Hypothesis}

Our main hypothesis is based on Selten's generalized equity principle. As shown, we can derive different reasonable distribution rules from this principle for our treatments. Previous studies mentioned in our literature review suggested that subjects tend to self-servingly apply different distribution rules depending on the respective situation (e.g., having a larger or a smaller outside option). This leads us to our primary research hypothesis:

Hypothesis: Subjects apply the equity rules in a self-serving manner.

With respect to our experiment, we expect players with a higher outside option to prefer either PS or SD over EQ as they yield higher payoffs. Players with a lower outside option are expected to opt for an egalitarian distribution (i.e., to prefer EQ over SD or PS).

\section{Results}

This section is structured according to our main research question: How does the presence of outside options influence the employment of different equity rules? As the generalized equity principle provides precise point predictions, we first focus on the number of proposers' offers and responders' mao that are in line with one of the three equity rules. Thereby we go beyond previous studies which mainly focused on average behaviors. ${ }^{9}$

In order to investigate the relevance of equity rules, we count offers and maos that can be predicted by one of the equity rules proposed by Selten. We apply a strict point prediction classification to categorize subjects' decisions: We assume that a subject applies an equity rule if and only if she chooses the exact distribution suggested by this rule. The total

\footnotetext{
${ }^{9}$ When analyzing average offers and mao, we find that offers (mao) are higher the larger the outside option of the responder. Analogously, offers (mao) are lower the larger the outside option of the proposer (see Table A.2 and the regression analysis in Table A.2 in the Appendix; Figure 2 and Figure 3 show distributions of decisions for each treatment). This is in line with what has been observed in previous studies.
} 


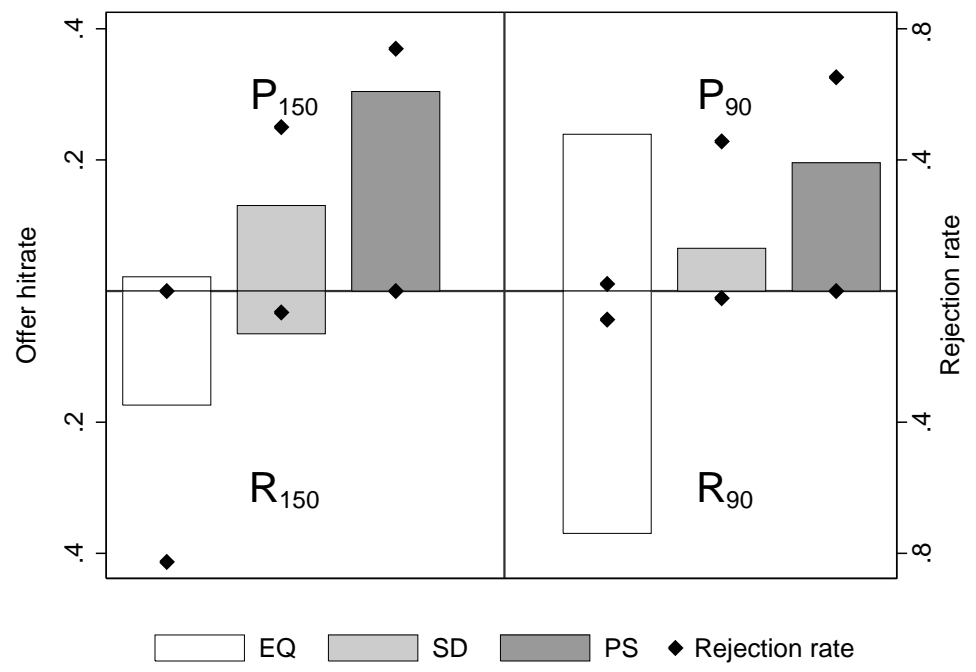

Figure 1: Hitrate and rejection rate for equity rules

number of exact hits relative to all decisions in a treatment will be denoted as the hitrate for a specific rule.

We test our hypothesis as follows: First, we separately compare the behavior of proposers and responders in treatments where the size of the larger outside option is the same but the holder in one treatment is the proposer and in one treatment is the responder. For example, we compare hitrates of a certain equity rule in $P_{90}$ and $R_{90}$ for proposers and responders. As previously described, each subject took part in two treatments with two different outside option constellations. We arranged the sequences of these treatments such that we can compare the usage of equity rules between and within subjects. Therefore, for each pairwise treatment comparison, we will present results from a between and a within subjects perspective. ${ }^{10}$

Our analysis of the generalized equity principle starts with the proposers' offers followed by an assessment of responders' mao. We then discuss efficiency.

\footnotetext{
${ }^{10}$ We use Fisher exact tests for the between subjects comparison and McNemar change tests for the within subject analysis. If not mentioned otherwise, as we have formulated a directed hypothesis, all statistical tests are carried out one-sided. As we find no systematic evidence that offers and mao are affected by the respective sequence, we merge sequences that contain the same two treatments (e.g. $P_{150}$, Baseline and Baseline, $\left.P_{150}\right)$. A battery of 24 Mann Whitney U tests pairwise comparing the distribution of offers and mao of the same treatment between different sequences yields no systematic significant differences (see Table A.1 in the Appendix).
} 
Offers and the Generalized Equity Principle To obtain a first estimate how equity rules influence offers, we pool all offers from all treatments and calculate the hitrate. A fraction of .43 of all offers are equitable offers in line with Selten's principle. ${ }^{11}$ This number appears to be remarkably high given our strict point prediction rule.

In Baseline, where outside options are of equal size, .51 of the subjects offer EQ. This does not come as a surprise because, as stated in section 3, all three equity rules suggest the same offer when outside options are symmetric.

The analysis of proposers' behavior in treatments with asymmetric outside options leads us to our first observation concerning the use of equity rules:

Observation 1: Proposers frequently apply the generalized equity principle. They do so in a self-serving way. Proportional splits are offered more often when proposers have the larger outside option. However, they rely more often on equal splits when the responder has the larger outside option.

Support for this observation can be found in Figure 1, which shows hitrates (bars) for each equity rule averaged over each of the four treatments with asymmetric outside options. It can be seen that PS explains offers particularly well, when the proposer has the larger outside option. EQ is most prevalent in offers when the responder has the larger outside option.

In Table 3, we depict the relative frequencies of exact hits for each equity rule per treatment. The left panel shows the data for sequences that contain one asymmetric treatment and Baseline. Comparing the hitrates between subjects, we find that PS is much more prevalent when proposers have the larger outside option ( $p=.005$ for $P_{150}$ vs. $R_{150} ; p=.011$, for $P_{90}$ vs. $\left.R_{90}\right)$. For EQ and SD, we observe that fractions point into the hypothesized direction, namely EQ is more frequent when the responder has the larger outside option whereas SD is more prevalent when the proposer has the larger outside option. However, we find only mild statistical evidence comparing $P_{150}$ and $R_{150}(p=.094)$ for EQ. This tendency gets further support by a within-subject comparison. Subjects significantly more often offer PS when they have a larger outside option of $150\left(p=.001\right.$, for $P_{150}$ vs. $\left.R_{150}\right){ }^{12}$

To capture the behavior of all subjects, we now go one step further and relax the strict point prediction rule and broaden our classification strategy. For each proposer's offer, we measure the absolute distance to all three equity rules. Offers are classified according to the

\footnotetext{
${ }^{11}$ This figure splits up for each treatment as follows: Baseline .51, $P_{150}: .46, R_{150}: .24, P_{90}: .5, R_{90}$ : .37. As a comparison, the hitrate for the sub-game perfect equilibrium (SP) is .06 (Baseline: .03, P150: .04, $\left.R_{150}: .26, P_{90}: .02, R_{90}: .04\right)$ off all offers.

${ }^{12}$ Interestingly, two proposers in $P_{150}$ make an offer that represents a deal me out solution (Anbarci and Feltovich, 2011), i.e., the proposer keeps her outside option (150 points) and offers the remainder to the responder (90 points). Note that this sharing rule is not in line with the generalized equity principle.
} 
Table 3: Hitrate of equity rules

\begin{tabular}{|c|c|c|c|c|c|c|}
\hline \multirow[b]{2}{*}{ Treatment } & \multicolumn{3}{|c|}{ Between Subjects } & \multicolumn{3}{|c|}{ Within Subjects } \\
\hline & EQ & $\mathrm{SD}$ & PS & EQ & $\mathrm{SD}$ & PS \\
\hline Baseline & .51 & & & & & \\
\hline$P_{150}$ & $\begin{array}{l}.04 \\
<^{*}\end{array}$ & .17 & $\begin{array}{l}.29 \\
>^{* * *}\end{array}$ & 0 & .10 & $\begin{array}{l}.32 \\
>^{* * *}\end{array}$ \\
\hline$R_{150}$ & .21 & .13 & 0 & .14 & 0 & 0 \\
\hline$P_{90}$ & .17 & .08 & $\begin{array}{l}.25 \\
>^{* *}\end{array}$ & .32 & .05 & .13 \\
\hline$R_{90}$ & .33 & 0 & 0 & .40 & 0 & 0 \\
\hline
\end{tabular}

Notes: The left panel shows the hitrate of equity rules from sequences that contained one asymmetric and one Baseline treatment. The right panel shows the hitrate for sequences with two asymmetric treatments. Stars display significance levels of comparisons of two asymmetric treatments. Significance levels: ${ }^{* * *} p<.01,{ }^{* *} p<.05,{ }^{*} p<.1$.

smallest distance to one of these rules. For example, we classify a proposer's offer as EQ when, among the three distances, the distance to EQ is the smallest. The results of this classification are shown in Table A.3 in the Appendix. The figures support the results from our very conservative approach, making them even stronger.

Using this measure as a dependent variable, we estimate simple linear probability models to further verify our results of Observation 1. In Table 4, we predict whether a proposer offers EQ, SD or PS on a treatment dummy while controlling for the sequence of treatments. Confirming the results of our non-parametric analysis, we find that PS in $P_{150}$ and $P_{90}$ is significantly more prevalent compared to $R_{150}$ and $R_{90}$, respectively.

In light of the hypothesized self-serving use of equity rules, the clear self-serving pattern of PS choices in $P_{150}$ vs. $R_{150}$ and $P_{90}$ vs. $R_{90}$ confirms our main research hypothesis: From the set of our three equity rules the PS rule yields the highest payoff for the player with the higher outside option. On the other hand, for the player with the smaller outside option, EQ yields the highest payoff, which is partially confirmed by our results.

On the other hand EQ, is significantly less likely to be offered when the proposer has a larger outside option.

Thus far, we have focused on proposers' behavior in ultimatum games with asymmetric outside options. We find that 1) the equity principle is frequently used and 2) it is applied self-servingly. In the subsequent paragraphs, we shed light on responders' behavior to 
Table 4: Predicting hitrates of equity rules

\begin{tabular}{lcccccc}
\hline & $(1)$ & $(2)$ & $(3)$ & $(4)$ & $(5)$ & $(6)$ \\
& EQ & SD & PS & EQ & SD & PS \\
\hline \multirow{2}{*}{1 if $P_{150}$} & & & & & & \\
& $-0.136^{*}$ & 0.091 & $0.318^{* * *}$ & & & \\
1 if $P_{90}$ & $(0.07)$ & $(0.06)$ & $(0.10)$ & & & \\
& & & & -0.091 & 0.045 & $0.136^{*}$ \\
Constant & $0.136^{*}$ & -0.008 & 0.015 & 0.174 & 0.121 & 0.030 \\
& $(0.07)$ & $(0.10)$ & $(0.19)$ & $(0.12)$ & $(0.11)$ & $(0.12)$ \\
Observations & 92 & 92 & 92 & 92 & 92 & 92 \\
$\mathrm{R}^{2}$ & 0.087 & 0.068 & 0.189 & 0.062 & 0.103 & 0.149 \\
Sequence control & yes & yes & yes & yes & yes & yes \\
\hline
\end{tabular}

Notes: Linear probability models with robust standard errors (in parentheses) clustered on matching groups. The dependent variable EQ takes the value 1 if the offer is closer to the EQ prediction than to the prediction of the other two equity rules and 0 otherwise. Dependent variables SD and PS are constructed analogously. Each specification includes dummies for the specific sequence. Reference group (Constant) for (1)-(3) $R_{150}$, for (4)-(6) $R_{90}$. Significance levels: ${ }^{* * *} p<.01,{ }^{* *} p<.05,{ }^{*} p<.1$.

determine how different equity rules influence responders' minimum acceptable offers.

Rejections and the Generalized Equity Principle Employing again a strict point prediction rule, $25.7 \%$ of all maos can be classified as representing at least one of the three equity rules. ${ }^{13}$ This fraction is somewhat lower than found in proposers' choices.

For a more informative analysis of responders' behavior, in the following we consider hypothetical rejection rates. ${ }^{14}$ Hypothetical rejection rates of an equity rule in a treatment are calculated by matching the point prediction of an equity rule with every mao made in this treatment and determining the frequencies of rejections. The results are displayed in Table 5. The left panel shows between-subject comparisons and the right panel within-subject comparisons. Statistical tests lead to our second observation:

Observation 2: Responders are more likely to reject $P S$ and SD offers when proposers have the larger outside option. They reject EQ offers more often in $R_{150}$.

In Figure 1, we also depict the rejection rates (black diamonds) for each equity rule for all four treatments with asymmetric outside options. Responders tend to reject PS and SD

\footnotetext{
${ }^{13}$ In comparison $20 \%$ of maos are decisions in line with the subgame perfect equilibrium (SP).

${ }^{14}$ We chose this procedure because it is much harder to infer a specific preference for an equity rule from responders' maos. A simple example might highlight this: Consider a responder in $P_{150}$ who sets her mao to 40. According to our strict point prediction rule she would be classified as PS. However, by setting this mao she does not exclude the two other equity rules as their prediction would also be accept with this mao. Thus, one cannot easily categorize maos using a strict point prediction rule.
} 
Table 5: Hypothetical rejection rates for equity rules

\begin{tabular}{|c|c|c|c|c|c|c|}
\hline \multirow[b]{2}{*}{ Treatment } & \multicolumn{3}{|c|}{ Between Subjects } & \multicolumn{3}{|c|}{ Within Subjects } \\
\hline & EQ & $\mathrm{SD}$ & PS & EQ & $\mathrm{SD}$ & PS \\
\hline Baseline & .07 & & & & & \\
\hline$P_{150}$ & $\begin{array}{l}0 \\
<* * *\end{array}$ & $\begin{array}{l}.46 \\
>^{* * *}\end{array}$ & $\begin{array}{l}.67 \\
>^{* * *}\end{array}$ & $\begin{array}{l}0 \\
<^{* * *}\end{array}$ & $\begin{array}{l}.55 \\
>^{* * *}\end{array}$ & $\begin{array}{l}.82 \\
>^{* * *}\end{array}$ \\
\hline$R_{150}$ & .83 & .08 & 0 & .82 & .05 & 0 \\
\hline$P_{90}$ & .04 & $\begin{array}{l}.42 \\
>^{* * *}\end{array}$ & $\begin{array}{l}.63 \\
>^{* * *}\end{array}$ & 0 & $\begin{array}{l}.50 \\
>^{* * *}\end{array}$ & $\begin{array}{c}.68 \\
>^{* * *}\end{array}$ \\
\hline$R_{90}$ & .13 & .04 & 0 & .05 & 0 & 0 \\
\hline
\end{tabular}

more often, when the proposer has the larger outside option whereas EQ is rejected more often when the responder has an outside option of $150 .{ }^{15}$

Statistical evidence is shown in Table 5. Responders are significantly more likely to reject PS and SD offers when proposers have the larger outside option. This holds for all comparisons of SD and PS for within and between-subject comparisons (all $p<.004$ ). A rejection of EQ is more likely when the outside option of the responder equals $150(p<.0001)$. We find no statistical evidence that responders are more likely to reject EQ when they have an outside option of $90 .{ }^{16}$

Pooling all data from the two treatments with the same larger outside option in a regression analysis and controlling for the sequence of treatments confirms the results (see Table 6). SD and, in particular (as the coefficients and the $\mathrm{R}^{2}$ of the respective models reveal), PS offers are more likely to be rejected by responders when proposers have the larger outside option.

Efficiency and Profits We conclude our results section by investigating the impact of different outside option schemes and equity rules on efficiency and players' profits. More specifically, two questions are considered: How do outside options affect efficiency? Is it

\footnotetext{
${ }^{15}$ Recall responder's payoff would be 120 in case of accepting EQ.

${ }^{16} \mathrm{~A}$ corresponding analysis of the subgame perfect division yields that responders are more willing to reject this distribution when they have the lower outside option.
} 
Table 6: Predicting rejections of equity rules

\begin{tabular}{lcccccc}
\hline & $(1)$ & $(2)$ & $(3)$ & $(4)$ & $(5)$ & $(6)$ \\
& EQ & SD & PS & EQ & SD & PS \\
\hline \multirow{2}{*}{1 if $P_{150}$} & $-0.818^{* * *}$ & $0.500^{* * *}$ & $0.818^{* * *}$ & & & \\
& $(0.10)$ & $(0.10)$ & $(0.08)$ & & & \\
1 if $P_{90}$ & & & & -0.045 & $0.500^{* * *}$ & $0.682^{* * *}$ \\
& & & & $(0.05)$ & $(0.10)$ & $(0.08)$ \\
Constant & $0.818^{* * *}$ & 0.083 & -0.068 & 0.129 & 0.000 & 0.068 \\
& $(0.10)$ & $(0.18)$ & $(0.13)$ & $(0.09)$ & $(0.20)$ & $(0.18)$ \\
& & & & & & \\
Observations & 92 & 92 & 92 & 92 & 92 & 92 \\
$\mathrm{R}^{2}$ & 0.707 & 0.300 & 0.627 & 0.132 & 0.284 & 0.507 \\
Sequence control & yes & yes & yes & yes & yes & yes \\
\hline
\end{tabular}

Notes: Linear probability models (OLS) with robust standard errors (in parentheses) clustered on matching groups. The dependent variable EQ is 1 if the mao rejects the offer predicted by EQ and 0 otherwise. Dependent variables SD and PS are constructed analogously. Each specification includes dummies for the specific sequence. Reference group (Constant) for (1)-(3) $R_{150}$, for (4)-(6) $R_{90}$. Significance levels: ${ }^{* * *} p<.01,{ }^{* *} p<.05,{ }^{*} p<.1$.

profitable for an individual player to have a (specific) outside option?

In our setup, efficiencies can only differ across treatments due to cases of rejection as the amount distributed in the case of agreement is 240 . Because the agreement amount always exceeds the sum of outside options, reaching an agreement is always efficient.

In our analysis, we calculate average relative efficiency gains and average relative additional profits. Average relative efficiency gains are calculated as the absolute efficiency gains (i.e., the amount generated in addition to the sum of outside options) in relation to the maximally possible efficiency gain (i.e., 240 minus the sum of outside options). Analogously, average relative additional profits are calculated as achieved profits additional to the outside options in relation to the maximally possible additional profits (i.e., 240 minus the players' outside option). Using these measures we account for the fact that the possible absolute efficiency gains and absolute additional profits differ across treatments. ${ }^{17}$

Observation 3: Average relative efficiency gains are lower in $P_{150}$ and $R_{150}$ compared to Baseline.

The left panel of Table 7 shows average relative efficiency gains for matching groups. In Baseline, the average relative efficiency gain is .69; however, this measure is .42 in both $P_{150}$ and $R_{150}$ ( $p=.0088, p=.0143$, Wilcoxon signed rank test for matched pairs, henceforth WSR test, two-sided). In $P_{90}$ and $R_{90}$ we observe no significant difference in average relative efficiency gains compared to Baseline. ${ }^{18}$

\footnotetext{
${ }^{17}$ For absolute values on these measures see Table A.4.

${ }^{18}$ For this comparison, we focus on the data from sequences where matching groups went through a sequence of Baseline and the respective asymmetric treatment.
} 
Table 7: Average relative efficiency gains \& profits

\begin{tabular}{|c|c|c|c|}
\hline \multirow[b]{2}{*}{ Treatment } & \multirow{2}{*}{$\begin{array}{l}\text { Avg. relative } \\
\text { efficiency gain }\end{array}$} & \multicolumn{2}{|c|}{ Avg. rel. add. profits } \\
\hline & & Proposer & Responder \\
\hline Baseline & .69 & .31 & .17 \\
\hline$P_{150}$ & $.42^{* * *}$ & $.05^{* * *}$ & $.03^{* * *}$ \\
\hline$R_{150}$ & $.42^{* *}$ & $.09^{* * *}$ & $-.07^{* * *}$ \\
\hline$P_{90}$ & .58 & .24 & .08 \\
\hline$R_{90}$ & .71 & .29 & $.06^{* *}$ \\
\hline
\end{tabular}

Notes: The left panel displays average values of relative efficiency gains. The right panel depicts the relative additional profits realized by both player types. Average values are based on matching group-level data and from sequences that involve Baseline and one asymmetric treatment in order to make appropriate non-parametric comparisons. Including data from all sequences does not change average values substantially.

Stars display the significance levels of a Wilcoxon signed rank test for matched pairs comparing results from the Baseline against the respective asymmetric treatment. Significance levels: ${ }^{* * *} p<.01,{ }^{* *}$ $p<.05,{ }^{*} p<.1$.

Observation 4: Average relative additional profits are lower in $P_{150}$ and $R_{150}$ compared to Baseline.

The right panel of Table 7 displays average relative increases in profits for both players. In Baseline, proposers (responders) realize additional profits of .31 (.17). Having an outside option of 150 induces an increase in additional profits of only .07 (-.06) for proposers (responders). Compared to Baseline, these amounts are significantly lower (both $p<.01$, WSR test). In $R_{90}$ we find a similar tendency (.04, $p=.0223$, WSR test). In $P_{90}$, the relative additional profits are not statistically different from Baseline ( $p=.4222$, WSR test).

\section{Discussion and Conclusion}

In this study, we provide systematic evidence that different equity notions (Selten, 1978) in bargaining situations with asymmetric outside options are deeply rooted in behavior. We find that asymmetric outside option constellations make it harder for bargainers to reach an agreement and extend the existing literature by tracing different notions of what participants consider to be suitable allocations. By employing the generalized equity principle (Selten, 1978), we identify three different equity rules that we make clearly distinguishable by our experimental design. We find clear evidence that proposers' offers are in line with these 
simple equity rules - taken all games together, we find that $43 \%$ of all offer decisions precisely follow the generalized equity principle. The high number of proposers who try to solve the asymmetric outside option bargaining by implementing an equitable outcome is remarkable.

However, using our experimental design, we are able to show that equity rules are not applied in a consistent manner, but rather self-servingly. More specifically, proposers are inclined to offer proportional splits when these serve their own interests. Yet proposers tend to offer equal distributions when the responder would benefit from a proportional split. At the same time, we observe that responders are reluctant to accept proportional divisions when they are to their disadvantage in comparison to an equal split. Responders tend to accept proportional distributions only when they benefit from them. In sum, equity rules seem to be attractive for guiding behavior by adhering (or maybe pretending to adhere) to some equity considerations. However, equity rules are rather chosen in a self-serving manner. This inconsistent application of equity rules and its conflict-enhancing effect might well be the reason for low efficiency gains when bargainers have asymmetric outside options.

Our results underscore and extend the general validity of models of inequity aversion (Fehr and Schmidt, 1999; Bolton and Ockenfels, 2000). These models rely on an understanding of what constitutes an equitable outcome. Based on this reference point, individuals evaluate inequity which influences their utility. However, as our study demonstrated, there is not a unique reference point of equity but several potential candidates might be relevant. Models of inequity aversion can be applied to each of the three previously discussed equity norms. We find, that their adoption as equity might depend on the individual perspective and appears to be self-serving. Thus, our results highlight that there might be a need to consider different reference points for different parties involved when applying models of inequity aversion. ${ }^{19}$

Our empirical findings strongly underscore doubts about a clear predominance of one specific fairness rule which is often suggested by normative models of distributive justice (Gärtner and Schokkaert, 2012). In our experiment, we employ outside options as a rather self-evident and exogenously provided standard of comparison. In bargaining situations outside the laboratory, it is quite often the case that a plethora of standards of comparison are available, such as in the negotiation about the manager's compensation discussed in the introduction. When the manager and the potential employer bargain over the split of the profits, outside options might not be the only reasonable standard of comparison; the efforts and investments of both parties might also contribute in the future. Likewise, in a

\footnotetext{
${ }^{19}$ In this respect, our findings are in line with the literature on the 'moral wiggle room' (Dana et al., 2007), in the sense that bargaining parties have some freedom to strategically select the 'right' equity rule. It is also related to the concept of 'bounded ethicality' (Chugh et al., 2005; Bazerman and Tenbrunsel, 2011) as subjects might actually be convinced that their adopted equity rule is actually the 'right' one while ignoring that other parties might adopt a different one.
} 
merger between two companies, the standard of comparison for the distribution of future gains could be based on other factors than outside options, such as the pre-merger market share or the invested amounts.

In light of our results on the self-serving usage of equity rules, one might think that bargaining parties will strive not only for the equity rule most beneficial for them, but rather for a standard of comparison that leads to a justifiable (self-serving) distribution. Therefore, we consider our results to be a lower bound for self-serving behavior. The room for disagreement in bargaining outside the laboratory might be larger because the standards of comparison are likely to be less self-evident in the field. Moreover, outside options might not always be randomly assigned as in our experiment, but could be costly to acquire. It might well be that the relevance of our three equity rules is more pronounced if outside options are earned.

Future research needs to explore how the observed imbalances in the application of equity notions might be mitigated by, for example, explicitly taking the perspective of the other negotiator or investigating other procedures to harmonize the perceptions of equity (Bhatt and Camerer, 2005; Costa-Gomez and Crawford, 2006). One step in this direction might be further research into why equity rules are adopted: Are they primarily employed because of self-image concerns or because of the (maybe unwarranted) hope that the opponent in the negotiation might be more ready to agree if an equity norm is applied? 


\section{References}

Adams, J. S., 1965. Equity in social exchange. In: Berkowitz, L. (Ed.), Advances in Experimental Social Psychology. Vol. 2. pp. 267-299.

Anbarci, N., Feltovich, N., 2011. How responsive are people to changes in their bargaining position? Earned bargaining power and the 50-50 norm. School Working Paper Economics Series 2.

Aristotle, 2009. The Nicomachean Ethics. Oxford University Press.

Babcock, L., Loewenstein, G., 1997. Explaining bargaining impasse: The role of self-serving biases. Journal of Economic Perspectives 11 (1), 109-126.

Babcock, L., Loewenstein, G., Issacharoff, S., Camerer, C. F., 1995. Biased judgments of fairness in bargaining. The American Economic Review 85 (5), 1337-1343.

Babcock, L., Wang, X., Loewenstein, G., 1996. Choosing the wrong pond: Social comparisons in negotiations that reflect a self-serving bias. The Quarterly Journal of Economics $111(1), 1-19$.

Bazerman, M., Tenbrunsel, A., 2011. Blind Spots. Princeton University Press.

Bhatt, M., Camerer, C. F., August 2005. Self-referential thinking and equilibrium as states of mind in games: fmri evidence. Games and Economic Behavior 52, 414-459.

Bolton, G. E., Ockenfels, A., 2000. Erc: A theory of equity, reciprocity, and competition. The American Economic Review 90 (1), 166-193.

Bosmans, K., Schokkaert, E., 2009. Equality preference in the claims problem: A questionnaire study of cuts in earnings and pensions. Social Choice and Welfare 33, 533-557.

Cappelen, A. W., Hole, A. D., Sorensen, E. O., Tungodden, B., 2007. The pluralism of fairness ideals: An experimental approach. The American Economic Review 97 (3), 818 827.

Chiu, Y. S., Yang, B. R., 1999. The outside option, threat point, and nash bargaining solution. Economics Letters 62 (2), 181-188.

Chugh, D., Bazerman, M. H., Banaji, M. R., 2005. Bounded ethicality as a psychological barrier to recognizing conflicts of interest. Conflict of interest: Challenges and solutions in business, law, medicine, and public policy, 74-95.

Cook, K. S., Hegtvedt, K. A., 1983. Distributive justice, equity, and equality. Annual Review of Sociology 9, 217-241.

Costa-Gomez, M. A., Crawford, V. P., 2006. Cognition and behavior in two-person guessing games: An experimental study. The American Economic Review 96 (5), 1737-1768.

Dana, J., Weber, R. A., Kuang, J. X., 2007. Exploiting moral wiggle room: Experiments demonstrating an illusory preference for fairness. Economic Theory 33 (1), 67-80. 
Deutsch, M., 1975. Equity, equality, and need: What determines which value will be used as the basis of distributive justice? Journal of Social Issues 31 (3), 137-149.

Fehr, E., Schmidt, K. M., 1999. A theory of fairness, competition, and cooperation. The Quarterly Journal of Economics 114 (3), 817.

Fischbacher, U., 2007. z-tree: Zurich toolbox for ready-made economic experiments. Experimental Economics 10 (2), 171-178.

Fischer, S., 2005. Inequality aversion in ultimatum games with asymmetric conflict payoffs. Working Paper.

Fisher, R., Ury, W. L., 1991. Getting to Yes: Negotiating agreement without giving in, 2nd Edition. Penguin (Non-Classics).

Gächter, S., Riedl, A., 2005. Moral property rights in bargaining with infeasible claims. Management Science 51 (2), 249-263.

Gächter, S., Riedl, A., 2006. Dividing justly in bargaining problems with claims. Social Choice and Welfare 27 (3), 571-594.

Gärtner, W., Schokkaert, E., 2012. Empirical Social Choice Questionnaire-Experimental Studies on Distributive Justice. Cambridge University Press.

Greiner, B., 2003. An online recruitment system for economic experiments. In: Kurt Kremer, V. M. (Ed.), Forschung und wissenschaftliches Rechnen. GWDG Bericht 63. pp. 79-93.

Güth, W., 1995. On ultimatum bargaining experiments-a personal review. Journal of Economic Behavior \& Organization 27 (3), 329-344.

Güth, W., Schmittberger, R., Schwarze, B., 1982. An experimental analysis of ultimatum bargaining. Journal of Economic Behavior \& Organization 3, 367-388.

Güth, W., Tietz, R., 1990. Ultimatum bargaining behavior: A survey and comparison of experimental results. Journal of Economic Psychology 11 (3), 417-449.

Hennig-Schmidt, H., Leopold-Wildburger, U., Ostmann, A., Van Winden, F., 2010. Understanding negotiations: A video approach in experimental gaming. In: Ockenfels, A., Sadrieh, A. (Eds.), The Selten School of Behavioral Economics - A collection of essays in honor of Reinhard Selten. Springer-Verlag, Ch. 10, pp. 127-165.

Hennig-Schmidt, H., Li, Z.-Y., Yang, C., 2008. Why people reject advantageous offers Non-monotonic strategies in ultimatum bargaining: Evaluating a video experiment run in PR china. Journal of Economic Behavior \& Organization 65 (2), 373-384.

Homans, G. C., 1958. Social behavior as exchange. American Journal of Sociology 63 (6), 597-606.

Kagel, J. H., Kim, C., Moser, D., 1996. Fairness in ultimatum games with asymmetric information and asymmetric payoffs. Games and Economic Behavior 13 (1), 100-110. 
Knez, M. J., Camerer, C. F., 1995. Outside options and social comparison in three-player ultimatum game experiments. Games and Economic Behavior 10 (1), 65-94.

Kohnz, S., Hennig-Schmidt, H., 2005. Asymmetric outside options in ultimatum bargaining - An experimental study. Working Paper.

Konow, J., 2000. Fair shares: Accountability and cognitive dissonance in allocation decisions. The American Economic Review 90 (4), 1072-1091.

Konow, J., 2003. Which is the fairest one of all? A positive analysis of justice theories. Journal of Economic Literature 41 (4), 1188-1239.

Konow, J., 2005. Blind spots: The effects of information and stakes on fairness bias and dispersion. Social Justice Research 18 (4), 349-390.

Lange, A., Löschel, A., Vogt, C., Ziegler, A., 2010. On the self-interested use of equity in international climate negotiations. European Economic Review 54 (3), 359-375.

Malhortra, D., Bazerman, M. H., 2008. Negotiation Genius: How to Overcome Obstacles and Achieve Brilliant Results at the Bargaining Table and Beyond. Bantam Books.

Messick, D. M., 1993. Equality as a decision heuristic. In: Mellers, B. A., Baron, J. (Eds.), Psychological Perspectives on Justice. Cambridge University Press, pp. 11-31.

Messick, D. M., Sentis, K. P., 1979. Fairness and preference. Journal of Experimental Social Psychology 15 (4), $418-434$.

Nash, J., 1953. Two-person cooperative games. Econometrica 21, 128-140.

Pillutla, M. M., Murnighan, J. K., 1995. Being fair or appearing fair: Strategic behavior in ultimatum bargaining. Academy of Management Journal 38 (5), 1408-1426.

Rode, J., Menestrel, M. L., 2011. The influence of decision power on distributive fairness. Journal of Economic Behavior \& Organization 79 (1), 246-255.

Rodriguez-Lara, I., Moreno-Garrido, L., 2012. Self-interest and fairness: Self-serving choices of justice principles. Experimental Economics 15 (1), 158-175.

Roth, A. E. (Ed.), 1988. The Shapley Value: Essays in Honor of Lloyd S. Shapley. Cambridge University Press.

Schmitt, P. M., 2004. On perceptions of fairness: The role of valuations, outside options, and information in ultimatum bargaining games. Experimental Economics 7 (1), 49-73.

Selten, R., 1978. The equity principle in economic behavior. In: Decision Theory, Social Ethics, Issues in Social Choice. Gottinger, Hans-Werner and Leinfellner, Werner, pp. 269-281.

Shapley, L. S., 1953. Contributions to the Theory of Games. Princeton University Press, Ch. A Value for n-person Games, pp. 307-317.

Soudek, J., 1952. Aristotle's theory of exchange: An inquiry into the origin of economic analysis. Proceedings of the American Philosophical Society 96 (1), 45-75. 
Walster, E., Berscheid, E., Walster, W. G., 1973. New directions in equity research. Journal of Personality and Social Psychology 25 (2), 151-176.

Young, H. P., 1995. Equity - In Theory and Practice. Princeton University Press. 


\section{Appendix A - Tables and Figures}

Table A.1: Overview of sequences and results

\begin{tabular}{|c|c|c|c|c|c|c|c|c|c|}
\hline \multirow{3}{*}{ Sequence } & \multirow{3}{*}{$\begin{array}{c}\text { No. } \\
\text { of Subjects }\end{array}$} & & & \multicolumn{3}{|c|}{ Average offer } & \multicolumn{3}{|c|}{ Average mao } \\
\hline & & \multicolumn{2}{|c|}{ Order of treatments } & \multicolumn{2}{|l|}{ Asym } & \multirow[t]{2}{*}{ Baseline } & \multirow[t]{2}{*}{ Asym } & & \multirow[t]{2}{*}{ Baseline } \\
\hline & & $1 \mathrm{st}$ & $2 \mathrm{nd}$ & & & & & & \\
\hline 1 & 24 & $P_{150}$ & Baseline & 50.83 & $<* * *$ & 110.00 & 68.00 & $<* * *$ & 108.25 \\
\hline 2 & 24 & Baseline & $P_{150}$ & 62.92 & $<* * *$ & 115.41 & 54.00 & $<* *$ & 87.58 \\
\hline 3 & 24 & $R_{150}$ & Baseline & 125.00 & $>^{* * *}$ & 95.00 & 152.08 & $>^{* * *}$ & 92.58 \\
\hline 4 & 24 & Baseline & $R_{150}$ & 146.24 & $>^{* *}$ & 108.33 & 153.00 & $>^{* * *}$ & 100.00 \\
\hline 5 & 24 & $P_{90}$ & Baseline & 78.00 & $<* * *$ & 106.67 & $96.25^{+}$ & $<$ & 102.75 \\
\hline 6 & 24 & Baseline & $P_{90}$ & 82.58 & $<$ & 93.42 & 70.08 & $<$ & 73.92 \\
\hline 7 & 24 & $R_{90}$ & Baseline & 117.08 & $>^{* * *}$ & 92.50 & 111.67 & $>$ & 99.92 \\
\hline \multirow[t]{2}{*}{8} & 24 & Baseline & $R_{90}$ & 116.33 & $>$ & 104.25 & 106.75 & $>^{* * *}$ & 81.00 \\
\hline & & & & $P_{o_{i}}$ & & $R_{o_{j}}$ & $P_{o_{i}}$ & & $R_{o_{j}}$ \\
\hline 9 & 24 & $P_{150}$ & $R_{150}$ & 57.00 & $<^{* * *}$ & 140.92 & $77.50^{+}$ & $<* * *$ & 154.58 \\
\hline 10 & 20 & $R_{150}$ & $P_{150}$ & 54.00 & $<^{* * *}$ & 151.40 & 56.60 & $<* * *$ & 155.90 \\
\hline 11 & 24 & $P_{90}$ & $R_{90}$ & 93.33 & $<* * *$ & 120.83 & 84.33 & $<^{*}$ & 99.42 \\
\hline 12 & 20 & $R_{90}$ & $P_{90}$ & 88.00 & $<^{* * *}$ & 111.80 & 77.00 & $<^{*}$ & 98.10 \\
\hline (Pooled) & 192 & \multicolumn{2}{|c|}{ Baseline } & \multicolumn{3}{|c|}{103.20} & \multicolumn{3}{|c|}{93.25} \\
\hline (Pooled) & 92 & \multicolumn{2}{|c|}{$P_{150}$} & \multicolumn{3}{|c|}{56.40} & \multicolumn{3}{|c|}{64.35} \\
\hline (Pooled) & 92 & \multicolumn{2}{|c|}{$R_{150}$} & \multicolumn{3}{|c|}{140.48} & \multicolumn{3}{|c|}{153.80} \\
\hline (Pooled) & 92 & \multicolumn{2}{|c|}{$P_{90}$} & \multicolumn{3}{|c|}{85.37} & \multicolumn{3}{|c|}{82.13} \\
\hline (Pooled) & 92 & \multicolumn{2}{|c|}{$R_{90}$} & \multicolumn{3}{|c|}{116.71} & \multicolumn{3}{|c|}{104.24} \\
\hline
\end{tabular}

Notes: Stars display significance levels of a Wilcoxon signed-rank test for matched pairs comparing the distribution of decisions in the same sequence between different treatments. Significance levels: ${ }^{* * *} p<.01,{ }^{* *} p<.05,{ }^{*} p<.1$. Plus signs display the significance levels of a Mann-Whitney U-test comparing the distribution of decisions in the same treatment between different sequences. Significance levels: ${ }^{+} p<.1$. 
Table A.2: Estimating players decision

\begin{tabular}{|c|c|c|c|}
\hline & $\begin{array}{l}(1) \\
\text { offer }\end{array}$ & $\begin{array}{l}(2) \\
\text { mao }\end{array}$ & $\begin{array}{c}(3) \\
\text { reject }\end{array}$ \\
\hline$P_{150}$ & $\begin{array}{c}-55.81^{* * *} \\
(6.28)\end{array}$ & $\begin{array}{c}-30.45^{* * *} \\
(5.07)\end{array}$ & $\begin{array}{c}0.394^{* * *} \\
(0.12)\end{array}$ \\
\hline$R_{150}$ & $\begin{array}{c}34.02^{* * *} \\
(6.53)\end{array}$ & $\begin{array}{c}58.92^{* * *} \\
(4.96)\end{array}$ & $\begin{array}{c}0.283^{* *} \\
(0.12)\end{array}$ \\
\hline$P_{90}$ & $\begin{array}{c}-15.78^{* *} \\
(7.16)\end{array}$ & $\begin{array}{c}-8.618^{*} \\
(5.03)\end{array}$ & $\begin{array}{l}0.128 \\
(0.12)\end{array}$ \\
\hline$R_{90}$ & $\begin{array}{c}14.37^{* * *} \\
(4.95)\end{array}$ & $\begin{array}{c}12.39^{* * *} \\
(3.89)\end{array}$ & $\begin{array}{c}-0.0694 \\
(0.12)\end{array}$ \\
\hline Constant & $\begin{array}{c}108.3^{* * *} \\
(6.22)\end{array}$ & $\begin{array}{c}93.13^{* * * *} \\
(3.77)\end{array}$ & \\
\hline Observations & 280 & 280 & 280 \\
\hline $\mathrm{R}^{2}$ & .465 & .43 & .109 \\
\hline Sequence control & yes & yes & yes \\
\hline $\begin{array}{l}\text { p-Values (Wald-test) } \\
H_{0}: \beta_{P_{150}}=\beta_{P_{90}} \\
H_{0}: \beta_{R_{150}}=\beta_{R_{90}}\end{array}$ & $\begin{array}{l}.0001 \\
.0001\end{array}$ & $\begin{array}{l}.0001 \\
.0001\end{array}$ & $\begin{array}{l}.3334 \\
.1210\end{array}$ \\
\hline \multicolumn{4}{|c|}{$\begin{array}{l}\text { Notes: Models (1) and (2) display the results of a GLS regres- } \\
\text { sion with random effects. Robust standard errors are shown in } \\
\text { parentheses. Model (1) contains proposers' offer, while model (2) } \\
\text { contains the data from responders. Model (3) is a probit estima- } \\
\text { tion. The reference category is Baseline (Constant). } \\
\text { In the lower panel we display p-Values of a Wald-test comparing } \\
\text { the size of coefficents for different treatments with asymmetric } \\
\text { outside options. }\end{array}$} \\
\hline
\end{tabular}



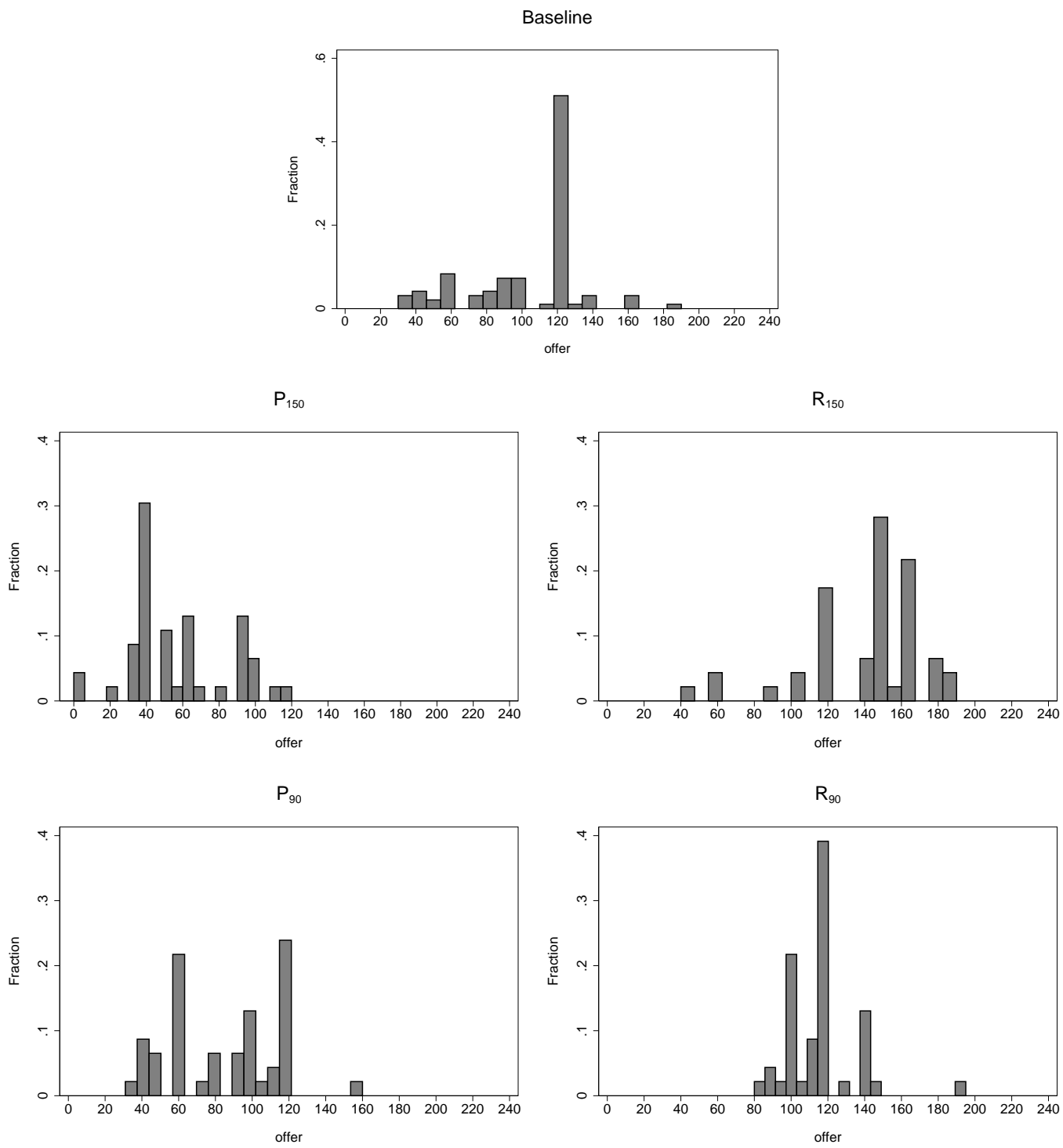

Figure 2: Distribution of offers in treatments 

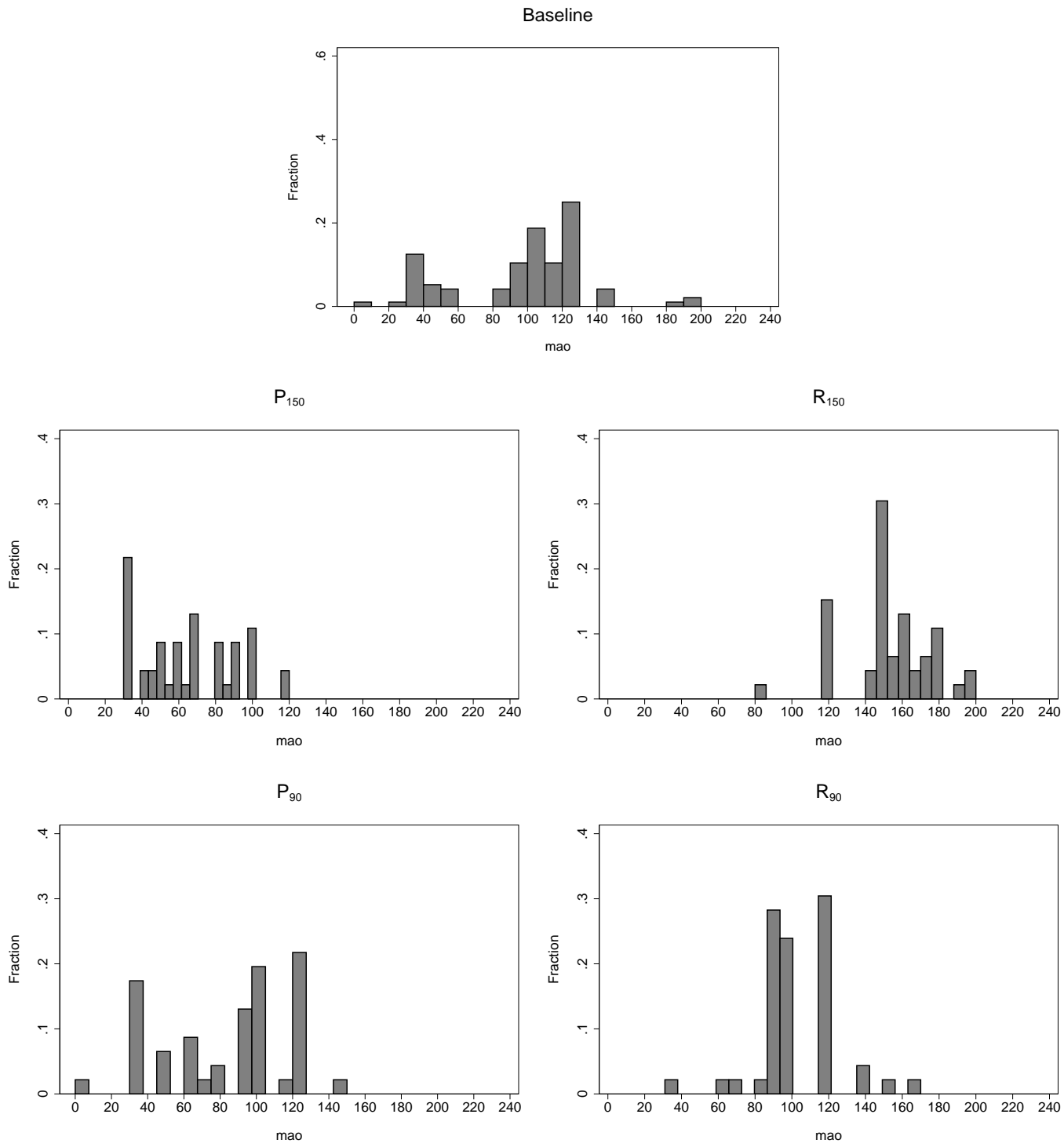

Figure 3: Distribution of mao in treatments 
Table A.3: Relaxed hitrate of equity rules (proposer)

Treatment
naseline

Table A.4: Average absolute efficiency gains \& profits

\begin{tabular}{|c|c|c|c|}
\hline \multirow[b]{2}{*}{ Treatment } & \multirow{2}{*}{$\begin{array}{l}\text { Avg. abs. } \\
\text { efficiency gain }\end{array}$} & \multicolumn{2}{|c|}{ Avg. abs. add. profits } \\
\hline & & Proposer & Responder \\
\hline Baseline & 123.75 & 95.57 & 66.30 \\
\hline$P_{150}$ & $25.00^{* * *}$ & $154.58^{* * *}$ & $35.33^{* * *}$ \\
\hline$R_{150}$ & $25.00^{* * *}$ & $49.71^{* * *}$ & $143.54^{* * *}$ \\
\hline$P_{90}$ & $70.00^{* *}$ & $126.00^{*}$ & 48.58 \\
\hline$R_{90}$ & $85.00^{*}$ & 90.79 & $98.42^{* * *}$ \\
\hline
\end{tabular}

Notes: The left panel displays average values of absolute efficiency gains. The right panel depicts the absolute additional profits realized by both player types. Average values are based on matching group-level data and from sequences that involve Baseline and one asymmetric treatment in order to make appropriate non-parametric comparisons. Including data from all sequences does not change average values substantially.

Stars display the significance levels of a Wilcoxon signed rank test for matched pairs comparing results from the Baseline against the respective asymmetric treatment. Significance levels: ${ }^{* * *} p<.01,{ }^{* *}$ $p<.05,{ }^{*} p<.1$. 


\title{
Appendix B - Instructions (translated from German)
}

\author{
Welcome to the experiment!
}

You are participating in an economic experiment and you have the possibility to earn a certain amount of money, which varies according to your decisions. Please read thoroughly the following descriptions.

During the experiment we will talk about "Taler" and not $€$. Hence, your payout will be initially calculated in "Taler". The achieved total amount of money of "Taler" will be converted into $€$ at the end of the experiment and then we will give you a cash payout, whereas

$$
10 \text { Taler }=0,6 €
$$

holds true.

\section{The decisions in the experiment}

At the beginning of the experiment all participants have been randomly divided into two groups - players in the role of $\mathbf{A}$ and players in the role of $\mathbf{B}$ - which will interact with each other during the experiment. You will get to know neither before nor after the experiment with whom you are interacting. At the beginning of the experiment you will be informed of whether you are player A or B which was determined randomly by drawing the cabin number.

The experiment is about splitting 240 "Taler" among player A and B. Player A makes a proposal of how to split the $\mathbf{2 4 0}$ "Taler" among player A and player B. Player B decides from which amount of money he is willing to accept the proposal of player A. After both players have made their decisions, the decisions will be compared.

If the proposal of allocation of player $A$ is in the area of acceptance of player $B$, then

- the 240 "Taler" will be split in accordance to the decisions.

If the proposal of allocation of player $A$ is not in the area of acceptance of player $B$, then

- player A and player B will each get a guaranteed amount of money, which can be identical or different for player A and player B. Both player A and player B know the two guaranteed money amounts before the decisions are made.

Every player A interacts in two different, sequent games with two different players B.

Every player B interacts in two different, sequent games with two different players A.

If you are player A you will see this screen:

$$
\text { Game 1/Player A }
$$

Please note: In game 1 and game 2 you are interacting with different players B.

Please make a proposal of how to split the $\mathbf{2 4 0}$ "Taler" among you and player B.

Guaranteed amount of money for yourself, in the case of a rejection of player B: $\square$

Guaranteed amount of money for player B, in the case of an acceptance of player B: $\square$

The proposed amount of money for yourself: $\square$

This implies: The proposed amount of money for player B: $\square$ 
The decisions of player A and player B are made simultaneously. This implies for player B that he makes his decision before knowing which proposal player A will actually make.

\section{Game 1/Player B}

Please note: In game 1 and game 2 you are interacting with different players A.

Player A will make a proposal of how to split the $\mathbf{2 4 0}$ "Taler" among you and player A.

Please decide from which amount of money you are willing to accept the proposal of player A.

Guaranteed amount of money for player A, in the case of your rejection of the proposal: $\square$

Guaranteed amount of money for yourself, in the case of your acceptance of the proposal: $\square$

The lowest amount of money you are willing to accept: $\square$

This implies: The highest amount of money for player A you are willing to accept: $\square$

If the proposed amount of money of player A for player B is greater than or equal to the lowest amount of money player B is willing to accept, then the proposal will be accepted. Vice versa the proposal of player A will be rejected, if the proposed amount of money of player $A$ is smaller than the lowest amount of money player B is willing to accept.

Before the experiment starts we would like you to answer a couple of control questions. These questions will help you familiarize with the decision situation. At the end of the experiment we would like you to answer some further questions.

In the course of the experiment any form of communication with the other participants is forbidden. Please read now once again the instructions thoroughly to make sure that you understood everything. If there are any uncertainties left, please put your hand up. We will then come to you and answer your questions. 